\title{
Contaminación enteroparasitaria de intercomunicadores en edificios de Barquisimeto y Cabudare, Venezuela
}

\author{
Enteroparites contamination of intercoms \\ in buildings of Barquisimeto and Cabudare, Venezuela
}

Traviezo Valles Luis ${ }^{1,2,3}$, Machuca Beatriz ${ }^{1}$, López Ariana ${ }^{1,3}$, Jiménez Arturo ${ }^{1}$,

Lozada Wilmer $^{1}$, Lee Yerisbeth ${ }^{1}$, López María ${ }^{1}$

\section{Resumen}

Introducción. La falta de estudios en intercomunicadores como medios de propagación de enteroparásitos en Venezuela, motivó el presente estudio. Metodología. Se frotó el intercomunicador tres veces con un hisopo impregnado con solución salina 0,85\% (SSI), resuspendiéndolo en un tubo con $10 \mathrm{ml}$ de SSI, el cual se centrifugó a $3000 \mathrm{rpm}$ por 10 minutos para luego observar el sedimente al microscopio. Resultados. El 65\% de las muestras estuvieron contaminadas, encontrando 10 taxones de enteroparásitos, a saber: Blastocystis sp (49\% del total de muestras examinadas), Endolimax nana (36\%), Iodamoeba butschlii (8\%), Giardia lamblia (7\%), Entamoeba coli (4\%), Chilomastix mesnili (2\%), Entamoeba hartmanni (2\%), Trichuris trichiura (2\%), Hymenolepis nana (2\%) y Taenia sp (1\%). Discusión. La diversidad de parásitos encontrados y su abundancia, se corresponden con lo reportado en poblaciones de la misma zona. Conclusión. La falta de higiene en la mayoría de los intercomunicadores facilitan el potencial de estos para transmitir los parásitos endémicos del estado Lara.

Palabras claves: Parásitos, fómites, Blastocystis, Endolimax nana, Venezuela.

1. Universidad Centroccidental "Lisandro Alvarado" (UCLA), Decanato de Ciencias de la Salud, Barquisimeto, Venezuela.

2. UCLA, Sección de Parasitología Médica, Unidad de Investigación en Parasitología Médica (UNIPARME), Barquisimeto, Venezuela.

3. Fundación NaWaraos.

Correspondencia: Luis Traviezo, Avenida Andrés Bello con Av. Libertador, Sección de Parasitología, Barquisimeto, estado Lara, Venezuela. Móvil: 0580414 5244736,E-mail: luisetraviezo@hotmail.com y ltravies@ucla.edu.ve

ORCID:

https://orcid.org/0000-0003-4544-6965 - Traviezo Luis

https://orcid.org/0000-0001-7872-6889 - Machuca Beatriz

https://orcid.org/0000-0002-1865-0357 - López Ariana

https://orcid.org/0000-0002-2829-3373 - Lozada Wilmer

https://orcid.org/0000-0002-6672-3514 - Jiménez Arturo

https://orcid.org/0000-0002-2141-0346 - Lee Yerisbeth

Recibido: $10 / 01 / 2019$

https://orcid.org/0000-0002-2272-9551 - López María 


\section{Abstract}

Introduction. The lack of studies in intercoms as means of propagation of enteroparasites in Venezuela, motivated the present study. Methodology. The intercom was rubbed three times with a swab impregnated with $0.85 \%$ saline solution (SSI), resuspending it in a tube with $10 \mathrm{ml}$ of SSI, which was centrifuged at $3000 \mathrm{rpm}$ for 10 minutes to then observe the pellet under a microscope. Results. $65 \%$ of the samples were contaminated, finding 10 taxa of enteroparasites, namely: Blastocystis sp (49\% of the samples examined), Endolimax nana (36\%), Iodamoeba butschlii (8\%), Giardia lamblia (7\%), Entamoeba coli (4\%), Chilomastix mesnili (2\%), Entamoeba hartmanni (2\%), Trichuris trichiura (2\%), Hymenolepis nana (2\%) and Taenia sp (1\%). Discussion. The diversity of parasites found and their abundance correspond to that reported in populations of the same area. Conclusion. The lack of hygiene of most of the intercoms facilitates the potential of these to transmit the endemic parasites of the Lara State.

Keywords: Parasites, fomites, Blastocystis, Endolimax nana, Venezuela.

\section{Introducción}

En la historia de la humanidad las enfermedades parasitarias han ocasionado más muertes que todas las guerras que se hayan documentado hasta el presente (1) y de estas enfermedades, las enteroparasitosis representan un problema recurrente a nivel mundial que particularmente en Latinoamérica afecta entre un $20 \%$ a $30 \%$ de la población, esto sin agregar la presencia de portadores asintomáticos, no diagnosticados, que originan un subregistro de estas parasitosis (2). Se estima que, de $3500 \mathrm{mi}-$ llones de personas infectadas en el mundo, solo 450 millones manifiestan alguna sintomatología (2).

Las altas prevalencias están íntimamente asociadas a las modestas condiciones culturales y socioeconómicas, la falta de higiene, susceptibilidad del huésped, deficiencias en los servicios sanitarios, falta e inadecuada calidad del agua, escasa letrinización, insuficiencias en el sistema inmunológico, factores climáticos y geográficos, determinadas condiciones ecológicos, abundancia de vectores mecánicos y principalmente la contaminación fecal $(1,2,3,4)$.

En el estado de Lara (estado Lara), Venezuela, la prevalencia de parásitos intestinales oscila entre un 27 a $71 \%$ de la población, siempre con predominio de protozoarios sobre helmintos, siendo Blastocystis sp (Bh), el principal parásito diagnosticado, seguido por el comensal Endolimax nana (En), de tal manera que estas dos especies representan la asociación parasitaria (especies juntas en un mismo individuo) más frecuente en pacientes de este estado, al igual que en otras regiones de Venezuela (5). 
En el estado Lara la contaminación enteroparasitaria de fómites (vector pasivo) es un elemento significativo en la transmisión, donde se ha detectado un 29\% de billetes contaminados principalmente con Blastocystis sp y Endolimax nana (6), igualmente en las hortalizas (lechugas) se ha conseguido hasta $71 \%$ de contaminación con una diversidad de 11 taxones, siendo nuevamente Blastocystis sp y E. nana los más comúnmente encontrados (7). Es por esto que no es de extrańar que objetos de uso común y público como los intercomunicadores, estén contaminados con formas evolutivas de enteroparásitos, información que a nivel mundial es escasa y dispersa, aunado a que en Venezuela no se ha descrito el tema.

Objetivos. Se realiza el presente estudio con el fin de determinar la presencia de parásitos intestinales que contaminen los intercomunicadores de edificios en las Ciudades de Barquisimeto y Cabudare, discriminando los distintos taxones presentes y categorizando la frecuencia de cada especie.

\section{Materiales y métodos}

\section{Tipo de Estudio}

Es de tipo observacional, subtipo descriptivo, prospectivo, transversal, con muestra no probabilística y accidental. Con un enfoque de análisis cuantitativo.

El estudio se realizó entre febrero y mayo del año 2019, en el eje comprendido entre las ciudades de Barquisimeto, municipio
Iribarren (LN $\left.10^{\circ} 03^{\prime} 55^{\prime \prime}-\mathrm{LO} 69^{\circ} 18^{\prime} 53^{\prime \prime}\right)$ y Cabudare, municipio Palavecino (LN $10^{\circ} 02^{\prime} 10^{\prime \prime}$ - LO 69 $15^{\prime} 41^{\prime \prime}$ ) ambas del estado Lara, Venezuela, poblaciones muy próximas una de la otra, ya que el alto crecimiento poblacional de los últimos veinticinco años hizo que se fusionaran como un gran centro poblado, donde en la actualidad se definen como el mayor polo urbano del estado Lara. En el caso de Barquisimeto, la ciudad presenta una altitud de 520 msnm precipitación media anual de 624 $\mathrm{mm}$; mientras que Cabudare presenta una altitud de $450 \mathrm{msnm}$ y una precipitación media anual de $757 \mathrm{~mm}$., ambas ciudades exhiben una temperatura media anual de $24,5^{\circ} \mathrm{C}$ y una clasificación climática de Semiárido Cálido (8).

\section{Procedimiento}

Se seleccionaron los intercomunicadores en buen funcionamiento de 100 edificios del eje urbano Barquisimeto-Cabudare, dispositivos que permitían a las personas desde fuera del edificio comunicarse con las que habitaban en cada uno de los apartamentos. La muestra sobre los intercomunicadores se obtenía por hisopado, donde se tomó un palillo de madera de $153 \mathrm{~mm}$ de largo, con solo una de sus puntas cubiertas con algodón estéril, que era humedecida en solución salina isotónica estéril al 0,85\% (SSI) esta punta húmeda se frotaba o arrastraba con movimiento rotatorio sobre la superficie del intercomunicador durante unos 30 segundos, luego se introducía en un tubo de ensayo (16 x $150 \mathrm{~mm}$ ) limpio de tapa de 
baquelita (rosca), el cual contenía $10 \mathrm{ml}$ de SSI estéril, se agitaba el hisopo dentro de la SSI, se sacaba el hisopo del tubo de ensayo y se repetía el procedimiento dos veces más, para finalmente colocar todo el hisopo dentro del tubo, se tapaba, rotulaba y se trasladaba en una cava cerrada a temperatura ambiente hasta el Laboratorio de Parasitología Médica de la Universidad Centroccidental "Lisandro Alvarado" (UCLA), Barquisimeto, para su procesamiento en un tiempo no mayor de 24 horas posteriores a la toma de la muestra.

En el laboratorio se destapaban los tubos, se agitaba el hisopo dentro de la SSI (para desprender las formas parasitarias residuales del algodón) y luego se sacaba el hisopo, posteriormente los tubos se calibraban, tapaban y se centrifugaban a 3000 rpm durante 10 minutos, seguidamente se descartaba el sobrenadante y el sedimento o pellet que quedaba se resuspendía para luego colocar una gota de este en lámina porta objeto, luego se ubicaba arriba la laminilla cubre objeto $22 \times 22 \mathrm{~mm}$, para inmediatamente observar en microscopio óptico (AxioLab, Carl Zeiss), con objetivo de 10X y luego con objetivo de 40X para apreciar mejor los detalles de las formas parasitarias observadas (Figura 1).

Figura 1. Técnica para recuperación de enteroparásitos de los intercomunicadores.
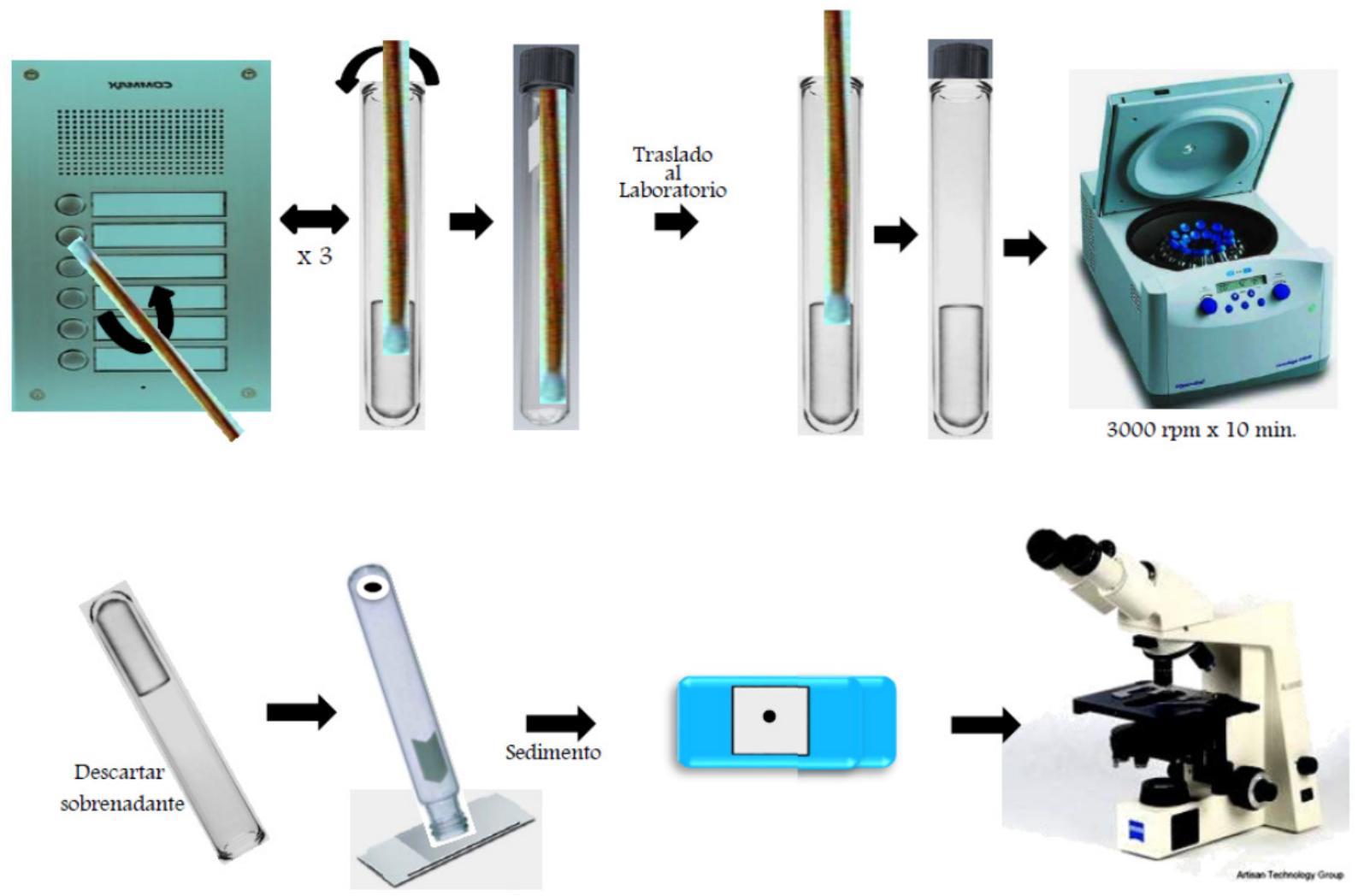

Fuente. Elaboración propia. 
Los intercomunicadores que no presentaron parásitos se identificaban como negativos o no contaminados, mientras que en los que se detectó, por lo menos, un estadio de protozoarios (quistes-ooquistes) o helmintos (huevos-larvas) se identificaban como positivos o contaminados. Los que presentaban una sola especie contaminando se rotulaban como "monocontaminados" y los que presentaban dos o más especies simultáneamente se identificaban como "policontaminados”.

\section{Resultados}

Se detectó que el 65\% de los intercomunicadores de los edificios analizados estuvieron contaminados con uno o más enteroparásitos, 31\% de las muestras analizadas estaban monocontaminadas mientras que un $34 \%$ de los analizados estaban policontaminados. De los edificios policontaminados 23 presentaron dos especies de parásitos, 9 edificios presentaron tres especies, 1 presentó cuatro especies y finalmente 1 presentó cinco especies.

Se consiguió una diversidad de diez taxones de enteroparásitos, tal que los protozoarios encontrados fueron: Blastocystis sp (49\% de las muestras examinadas), Endolimax nana (36\%), Iodamoeba butschlii (8\%), Giardia lamblia/G. intestinalis/G. duodenalis (7\%), Entamoeba coli (4\%), Chilomastix mesnili (2\%), Entamoeba hartmanni (2\%). Los helmintos fueron: Trichuris trichiura (2\%), Hymenolepis nana (2\%) y Taenia sp (1\%). De aquí se tiene que los enteroparásitos más abundantes (frecuentes) fueron Blastocystis sp y Endolimax nana (Figura 2).

Figura 2. Porcentaje de especies de enteroparásitos encontrados contaminando en los intercomunicadores de Barquisimeto y Cabudare.

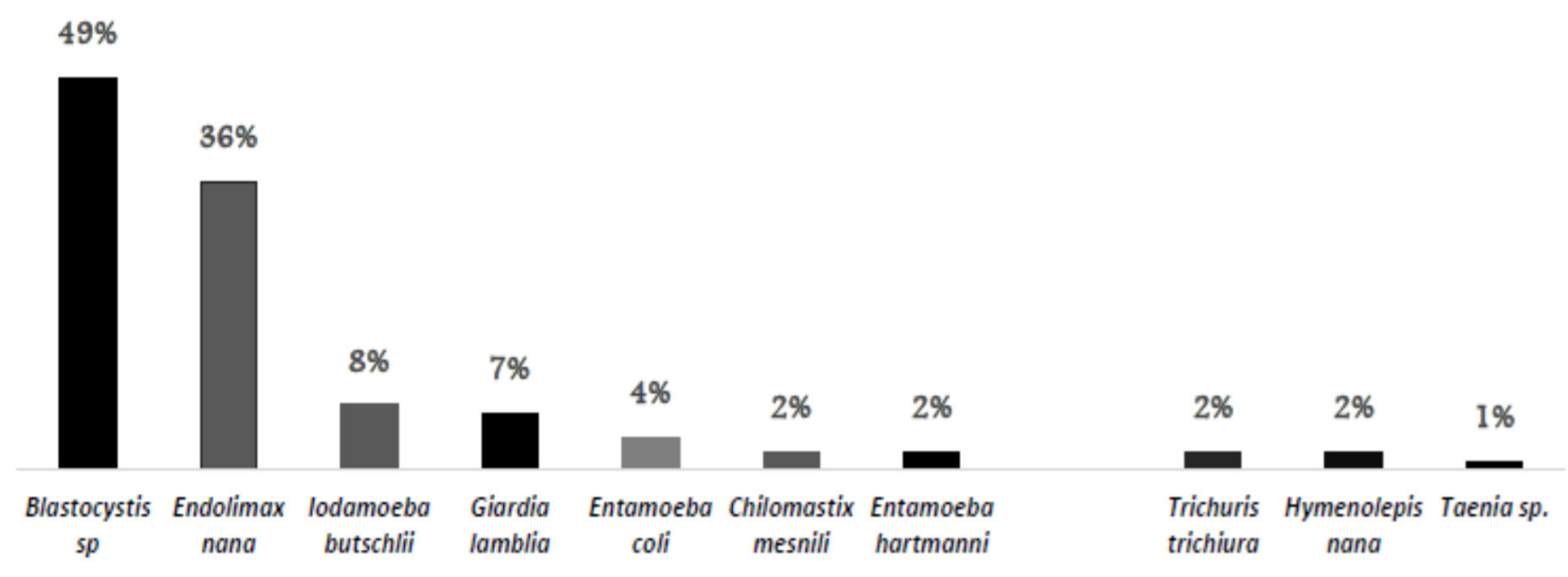

Fuente. Elaboración propia. 
La asociación de parásitos más frecuentemente encontrada (se conseguían juntos) fue la de Blastocystis sp con Endolimax nana ya que el $56 \%$ de los edificios policontaminados presentaban esta combinación.

Al discriminar la contaminación por zonas, se apreció que el 67\% del total de intercomunicadores de los edificios analizados en Barquisimeto (municipio Iribarren), estuvieron contaminados con por lo menos una especie de parásitos, mientras que en la ciudad de Cabudare (municipio Palavecino) el $52 \%$ de los intercomunicadores analizados estuvieron contaminados.

En las muestras no contaminadas y monocontaminadas se observaron también, escasas células epiteliales planas (CEP) procedentes de la superficie de la piel de los usuarios de los intercomunicadores, mientras que en la mayoría de las muestras policontaminadas (90\%) se observaron CEP de moderadas a abundantes (mayor cantidad).

Al georreferenciar los edificios analizados sobre el mapa satelital de ambas poblaciones se pudo apreciar que las áreas de mayor contaminación (mayor diversidad de especies) eran las más próximas a vías o avenidas de mayor tráfico humano y vehicular.

\section{Discusión}

La alta frecuencia de contaminación enteroparasitaria en estos intercomunicadores $(65 \%)$ los coloca por encima del riesgo que existe en el estado Lara por contaminación por otros fómites estudiados tales como los billetes que circulan en esta zona, 29\% (6) o contaminación en lechugas, 43\% (7).

La diversidad de parásitos encontrados fue muy amplia (diez taxones) y de estos, Blastocystis sp (49\% de los intercomunicadores estudiados) y Endolimax nana (36\%) fueron los más frecuentemente encontrados, tal como lo refieren trabajos internacionales en poblaciones de Costa Rica 24\% Bh y $8 \%$ En, (2), Cuba $87 \%$ Bh y $72 \%$ En (9), Bolivia 55\% Bh y $31 \%$ En (3), México $30 \%$ Bh y $29 \%$ En (1) y Colombia $58 \%$ $B h$ (10). También estos dos taxones son los más frecuentemente reportados en Venezuela, por ejemplo, en billetes que circulan en el estado Falcón, donde se presentan hasta con un $47 \%$ Bh y $17 \%$ En, respectivamente (11), situación que es también constante en estudios del estado Lara, con prevalencias de $\mathrm{Bh}$ en zonas rurales y urbanas, que oscilan entre un $27 \%$ a $71 \%$ (5). Esta alta frecuencia de $B h$ (único enteroparásito del reino Chromista que infecta al hombre) es importante desde el punto de vista clínico, ya que la blastocistosis, en el hombre, puede estar asociada a malestar general, alternancia de diarrea, tenesmo, náuseas, vómito, dolor abdominal, flatulencia, constipación, baja de peso, prurito anal, fiebre, anorexia, pérdida de sangre en las heces e incluso se relaciona con el síndrome de intestino irritable $(7,10,11)$.

Blastocystis sp es un parásito con una amplia capacidad para adaptarse y fijarse a cantidad de fómites, tal que ha sido encon- 
trado en uńas de pacientes $(42 \%$ del total de analizados), agua de panela (48\%), agua del grifo (39\%), juguetes (30\%), cáscaras de huevos (27\%), verduras (25\% a 65\%), biberones (19\%), también se ha señalado contaminando frutas, pisos de madera, pisos de tierra y baldosas, plasticidad adaptativa que podría explicar su alta prevalencia (10).

A pesar de que los valores de $B h$ que se reportan en intercomunicadores son más altos que los reportados en otros tipos de objetos inanimados $(75 \%$ de los intercomunicadores contaminados) estos deben ser aún mayores, ya que al procesar las muestras estas se centrifugan previamente y está descrito que este protozoario $(B h)$ se desfigura o se destruye con la centrifugación o se agrupa en la fase de anillos de residuos, lo cual dificulta y disminuye su diagnóstico $(9,10)$.

Con respecto al segundo patógeno más frecuente encontrado, Giardia lamblia/G. intestinalis/G. duodenalis (7\% de los intercomunicadores) tiene una prevalencia mundial que oscila entre $20 \%$ y $50 \%$, siendo uno de los enteroparásitos perjudiciales más comunes en niños de Colombia (11\%), Costa Rica (8\%) y de Cuba 7\% $(2,3,10)$ presentándose entre los tres enteroparásitos patógenos más frecuentes en pacientes del estado Lara y en lechugas y billetes (fómites) que circulan en la zona estudiada, también fue conseguido en el $7 \%$ de los billetes que transitan en la ciudad de Coro, Venezuela $(5,6,7,11)$.
Giardia lamblia tiene una gran importancia médica ya que se caracteriza por producir esteatorrea, mala absorción, náuseas, flatulencias acompañadas o no de disminución de la consistencia en las heces e incluso ha sido asociada a manifestaciones bucales tales como úlceras aftosas, glositis y queilitis $(1-7,9-11)$

Es importante señalar la presencia de moscas (vectores mecánicos) como un elemento resaltante en la diseminación de $B h$ (10), vectores que pudieron haber influido en el aumento de la contaminación de los intercomunicadores por $B h$ ya que durante el período de recolección de las muestras hubo en la zona de estudio irregularidad en la recolección de basura, lo que permite un aumento de las poblaciones de moscas, que en Cabudare han sido descritas con más de siete especies de moscas y que estas se encontraban contaminadas con ocho taxones distintos de enteroparásitos y de estos enteroparásitos los más frecuentes fueron, nuevamente, $B h$ y $E n$, lo cual coincide con el presente trabajo $(10,12)$.

Un elemento que potencia la supervivencia de los enteroparásitos sobre los intercomunicadores es que estos están hechos en su superficie (generalmente) de acero inoxidable (menos porosos) lo cual ha demostrado ser el mejor material para la "sobrevida" de formas de resistencia tales como ooquistes de Cryptosporidium sp y quistes de Giardia lamblia, comparándolos con supervivencias menores sobre superficies de piel, fórmica, cerámica y tela, ya que 
los espacios de acero tienen menores tasas de extinción (en el tiempo) que el resto de las superficies analizadas (más porosas) ya que los enteroparásitos en áreas de mayor porosidad pueden estar expuestos a un aumento del estrés osmótico. No obstante, en el caso de los billetes que circulan en Venezuela, que son fabricados a base de fibras de algodón y lino, estos presentan una zona rugosa y porosa que permite que quistes/ooquistes y huevos de enteroparásitos se adhieran con mayor facilidad $(6,11,13)$. También en muestras de Colombia se apreció para $B h$, mayor relación sobre su presencia en la superficie de pisos de madera y tierra, que sobre cerámica y cemento (10).

La mayoría de los intercomunicadores policontaminados están próximos a avenidas con alta circulación de vehículos y de personas, esto tal vez generaba mayores flujos de aire que resuspendían en el ambiente las formas infectantes de los parásitos, favoreciendo la contaminación externa de los edificios, ya que se ha demostrado que formas de resistencia de parásitos pueden permanecer nebulizadas (en aerosol) por la acción del viento hasta por tres semanas (11), igualmente la presencia de mayor contaminación en Barquisimeto que en Cabudare puede deberse a la mayor cantidad de población que habita en Barquisimeto, que es la capital del estado Lara y a mayor número de personas transitando, mayor probabilidad que un individuo con las manos sucias, toque y contamine el intercomunicador $(6,8,12)$.
Todos los elementos señalados confirman que lavarse las manos (antes de preparar los alimentos, comer o luego de ir al baño) es la medida clave para controlar la transmisión de enteroparásitos por contaminación por contacto con este tipo de fómites, ya que la falta de limpieza está íntimamente relacionada con la aparición de vómito y diarrea (1). La costumbre de lavado es, lamentablemente, escasa en Latinoamérica, por ejemplo, estudios en Perú señalan que solo el $11 \%$ de las personas se lavan las manos luego de defecar y el uso de jabón es aún menos frecuente (13).

La presencia de células epiteliales planas (CEP) de moderadas a abundantes, en las muestras policontaminadas, pudieran indicar que mayor cantidad de personas hicieron uso de estos intercomunicadores o que la limpieza de los mismos fue menos frecuente o que el mal funcionamiento de estos precisaba que los usuarios hicieran mayor presión con los dedos (superficie de la piel) en sus botones para comunicarse, en cualquiera de los casos la presencia de CEP fue proporcional a la abundancia y diversidad de enteroparásitos, por lo que el aumento de CEP en los sedimentos analizados podría utilizarse como un "indicador alterno" de posible contaminación parasitaria en los intercomunicadores. También es de resaltar que la presencia de materia orgánica (las CEP) en la superficie podría mejorar la supervivencia de las formas de resistencia de algunos enteroparásitos por lo que en el presente caso permitiría potenciar la transmisión $(10,13)$. 


\section{Conclusiones}

La contaminación del $65 \%$ de las muestras de intercomunicadores analizadas, con una diversidad de 10 taxones distintos de enteroparásitos, en su mayoría parásitos productores de enfermedades en el humano, indican el riesgo real de transmisión de enfermedades en estos lugares urbanos y, por consiguiente, la necesidad inmediata de limpiar periódicamente estas superficies con desinfectantes para neutralizar la transmisión de estos patógenos y de otros agentes infecciosos que pudieran estar asociados, tales como virus, bacterias y hongos.

\section{Consideraciones Éticas}

Se emplearon las normas de la Declaración de Helsinki, actualizada en: la Asamblea General de la Asociación Médica Mundial, en Fortaleza, Brasil, octubre del 2013.

\section{Agradecimientos}

A la Licenciada Elsys Cárdenas y a la Dra. María Isabel Najul por su colaboración.

\section{Conflicto de Intereses}

Los autores declaran no tener conflicto de intereses pertinentes a este artículo.

\section{Referencias}

1. Flores U, Franco L, Orozco N, Trejo I, Tlazola R, Barragán $\mathrm{N}$ et al. Enfermedades parasitarias dependientes de los estilos de vida. Journal of negative $\&$ no positive results. 2018; 3(6): 398-411.
2. Solano M, Montero A, León D, Santamaría C, Mora A, Reyes L. Prevalencia de parasitosis en niños de 1 a 7 años en condición de vulnerabilidad en la Región Central Sur de Costa Rica. Acta Médica Costarricense. 2018; 60(2): 19-29.

3. Villarroel M, Hidalgo R, Rojas S, Martínez G, Gómez M, Escalera D et al. Prevalencia de Enteroparasitosis en niños menores de 12 ańos que asisten a la Guardería Niño de Praga de la localidad de Tiquipaya de la ciudad de Cochabamba, Bolivia, durante el semestre II/2015. Revista de Investigación e Información en Salud. 2017; 29:24-30.

4. Lovón W, Tapia R. Manifestaciones clínicas bucales detectadas en pacientes con diagnóstico de amebiasis, giardiasis en el Centro de Salud de Yauri. Espinar, Cusco. Rev. Evid. Odontol. Clinic. 2018; $4(2): 1-8$.

5. Galíndez A, Cárdenas E, Traviezo L. Blastocystis sp, un protozoario endémico en el estado Lara, Venezuela. Bol Méd Post. 2016; 32(1):70-72.

6. Traviezo L, Cárdenas E, Jaspe G, Jaspe M, Heredia K, Morantes L, Agobian G. Enteroparásitos en papel moneda que circula en el eje Barquisimeto-Cabudare del estado Lara, Venezuela. Rev Vzlana Salud Pub. 2016; 4(2):23-26.

7. Traviezo L, Salas A, Lozada C, Cárdenas E, Martín J, Agobian G. Detección de enteroparásitos en lechugas que se comercializan en el estado Lara, Venezuela. Rev Méd-Cient "Luz Vida”. 2013;4(1):7-11.

8. Ministerio del Ambiente. Atlas del Estado Lara. 1998. Servicio Autónomo de Geografía y Cartografía Nacional. Barquisimeto, Venezuela.

9. Mendoza D, Núñez F, Escobedo A, Pelayo L, Fernández $\mathrm{M}$, Torres $\mathrm{D}$, et al. Utilidad de dos métodos coproparasitológicos y su empleo en un ensayo terapéutico antigiardiásico. Rev Cubana Med Trop. 2003; 55(3): 174-8.

10. Londońo-Franco A, Loaiza J, Lora F, Gómez J. Frecuencia y fuentes de Blastocystis sp. en niños de 0 a 5 años de edad atendidos en hogares infantiles 
públicos de la zona urbana de Calarcá, Colombia. Biomédica, 2014; 34: 218-227.

11. Morales P, Cazorla D, Antequera I, Navas P, Acosta M. Contaminación de billetes con enteroparásitos en Coro, estado Falcón, Venezuela. Bol Mal Salud Amb. 2014; 54(1): 38-46.

12. Traviezo L, Alejos M, Antonini M, Escobar C, Pérez $\mathrm{M}$, Pérez $\mathrm{F}$ et al. Contaminación enteroparasitaria de moscas capturadas en el municipio Palavecino, estado Lara, Venezuela. Rev Méd Urug. 2018; 34(4): 215-219.

13. Alum A, Absar I, Joseph H, Rubino J, Ijaz K . Impact of Environmental Conditions on the Survival of Cryptosporidium and Giardia on Environmental Surfaces. Interdiscip Perspect Infect Dis. 2014; 2014(210385):1-7. [Consultado 28 de abril 2019]. Disponible en: https://www.hindawi.com/journals/ ipid/2014/210385/

14. Camargo Castillo, N., \& Campuzano, S. (2006). Estudio piloto de detección de parásitos en frutas y hortalizas expendidas en los mercados públicos y privados de la ciudad de Bogota D.C. NOVA, 4(5). https://doi.org/10.22490/24629448.350 